\title{
Roles of ion-exchangeable sodium in the conversion process of tar to soot during rapid pyrolysis of two brown coals in a drop-tube reactor
}

Heming Dong, ${ }^{\dagger}$ Yu Zhang ${ }^{\dagger}$, Qian Du, ${ }^{*}$, Dun Li, ${ }^{\dagger}$ Dongdong Feng, ${ }^{\dagger}$ Jianmin Gao, ${ }^{\dagger}$ Shaohua Wu, Jiyi Luan

†School of Energy Science and Engineering, Harbin Institute of Technology, 92, Xidazhi Street, Harbin, Heilongjiang 150001, China

\$School of Mechanical Engineering, Jiamusi university, 258, Xuefu Street, Jiamusi, Heilongjiang 154007, China 


\section{Supporting Information}

Table S1 Main metal contents of two series of acid washed coal with different ion-exchangeable $\mathrm{Na}$ content (mass \%)

\begin{tabular}{ccccccc}
\hline Coal & $\mathrm{Na}$ & $\mathrm{K}$ & $\mathrm{Ca}$ & $\mathrm{Mg}$ & $\mathrm{Fe}$ & $\mathrm{Al}$ \\
\hline BKH & $0.0052 \%$ & $0.0046 \%$ & $0.0319 \%$ & $0.0041 \%$ & $0.0872 \%$ & $0.6876 \%$ \\
$\mathrm{BKNa} 1$ & $0.9176 \%$ & $0.0048 \%$ & $0.0264 \%$ & $0.0044 \%$ & $0.0974 \%$ & $0.7022 \%$ \\
$\mathrm{BKNa} 2$ & $1.5395 \%$ & $0.0064 \%$ & $0.0297 \%$ & $0.0038 \%$ & $0.0887 \%$ & $0.6931 \%$ \\
$\mathrm{BKNa} 3$ & $1.9220 \%$ & $0.0058 \%$ & $0.0247 \%$ & $0.0031 \%$ & $0.0781 \%$ & $0.6790 \%$ \\
\hline $\mathrm{ZDH}$ & $0.0089 \%$ & $0.0010 \%$ & $0.0358 \%$ & $0.0170 \%$ & $0.0824 \%$ & $0.1068 \%$ \\
$\mathrm{ZDNa} 1$ & $0.6772 \%$ & $0.0004 \%$ & $0.0116 \%$ & $0.0141 \%$ & $0.0789 \%$ & $0.1074 \%$ \\
$\mathrm{ZDNa} 2$ & $0.8222 \%$ & $0.0006 \%$ & $0.0444 \%$ & $0.0195 \%$ & $0.0977 \%$ & $0.1002 \%$ \\
$\mathrm{ZDNa} 3$ & $0.9352 \%$ & $0.0003 \%$ & $0.0194 \%$ & $0.0154 \%$ & $0.0675 \%$ & $0.1058 \%$ \\
\hline
\end{tabular}

